\title{
HINDLEG MUSCLE ENERGY AND SUBSTRATE BALANCES IN COLD-EXPOSED RATS
}

\author{
C. ADÁN, A. ARDÉVOL, X. REMESAR, M. ALEMANY* AND J. A. FERNÁNDEZ-LÓPEZ \\ Departament de Bioquímica i Fisiologia, Facultat de Biologia, Universitat de Barcelona, Barcelona, Spain
}

Accepted 1 February 1995

\begin{abstract}
Summary
Rats chronically cannulated in the carotid artery and the muscular branch of the femoral vein were subjected to a cold $\left(4^{\circ} \mathrm{C}\right)$ environment for up to $2 \mathrm{~h}$. The changes in blood flow (measured with ${ }^{46} \mathrm{Sc}$ microspheres) and arterio-venous differences in the concentrations of glucose, lactate, triacylglycerols and amino acids allowed the estimation of substrate (and energy) balances across the hindleg. Mean glucose uptake was $0.28 \mu \mathrm{mol} \mathrm{min}^{-1}$, mean lactate release was $0.33 \mu \mathrm{mol} \mathrm{min}^{-1}$ and the free fatty acid basal release of $0.31 \mu \mathrm{mol} \mathrm{min}-1$ was practically zero upon exposure to the cold; the initial uptake of triacylglycerols gave place to a massive release following exposure. The measurement of $P_{\mathrm{O}_{2}}, P_{\mathrm{CO}_{2}}$ and $\mathrm{pH}$ also allowed the estimation of oxygen, $\mathrm{CO}_{2}$ and bicarbonate balances and respiratory quotient changes across the hindleg. The contribution of amino acids to the energy balance of the hindleg was assumed to be low.

phases were observed in hindleg substrate utilization. (1) The onset of shivering, with the use of glucose/glycogen and an increase in lactate efflux. Lipid oxidation was practically zero (respiratory quotient near 1), but the uptake of triacylglycerols from the blood remained unchanged. (2) A substrate-energy shift, with drastically decreased use of glucose/glycogen, and of lactate efflux; utilization of triacylglycerol as practically the sole source of energy (respiratory quotient approximately 0.7 ); decreasing uptake of triacylglycerol and increased tissue lipid mobilization. (3) The onset of a new heat-homeostasis setting for prolonged cold-exposure, with maintenance of muscle energy and heat production based on triacylglycerol utilization and efflux from the hindleg (muscle plus skin and subcutaneous adipose masses) contributing energy to help sustain heat production by the core organs and surrounding brown adipose tissue.
\end{abstract}

These data were used to determine the sources of energy used to maintain muscle shivering with time. Three distinct
Key words: muscle, thermogenesis, heat balance, Wistar rat.

\section{Introduction}

Low temperatures pose a severe danger for function in mammals, since most cell reactions and processes are geared to function within narrow limits. Loss of heat results in lowered body temperatures, and many mechanisms cease to function or show altered operation or regulation (Gordon, 1990). Within certain limits, thermogenesis can cope with the heat loss of cold-exposure, depending on its capacity, the size (relative surface area) of the animal and the intensity of cold (Kleiber, 1972). For organisms adapted to cold environments, this problem is compensated by reducing surface area, increasing insulation (hair, blubber, etc.), increasing thermogenic capacity and consigning a higher proportion of energy to heat production and temperature maintenance (Brück and Zeisberger, 1987; Gordon, 1990).

The rat is a small mammal that thermoregulates well (Brück and Zeisberger, 1987; Gordon, 1990). It relies mainly on increased thermogenesis for maintenance of its temperature under conditions of cold-exposure or cold-acclimation (Gautier et al. 1991). In both processes, the involvement of brown adipose tissue (Foster and Frydman, 1978) and the adrenergic pathways (Bukowiecki et al. 1978) have been well documented, as has the increased blood pressure and work load (Fregly et al. 1989). The possible contribution of other organs, including the liver (Iossa et al. 1991) and kidneys, has also been reported.

The role of muscle shivering thermogenesis is often considered to be of short duration, helping to bridge the gap between the shock of rapid loss of heat subsequent to exposure to a cold environment and the full activation of other nonshivering thermogenic processes by brown fat, liver and other organs, including muscle (Davis et al. 1960; Gordon, 1990). The extent and frequency of shivering bouts have been studied (Yahata and Kuroshima, 1988), but the energy supply for muscle thermogenesis has not been determined. We have

*Author for correspondence. 


\section{C. AdÁN AND OTHERS}

studied the involvement of internal and blood-borne substrates in the fuelling of rat muscle heat production during the first $2 \mathrm{~h}$ of exposure to the cold $\left(4^{\circ} \mathrm{C}\right)$ environment.

\section{Materials and methods}

The animals studied were male albino Wistar rats of IffaCredo (France) stock, weighing 240-260 g; they were housed individually in polypropylene-bottomed cages with wood shavings as absorbent material. The cages were maintained in an environment with controlled light (on from 08:00 to 20:00 h), humidity $(70-80 \%)$ and temperature $\left(21-22^{\circ} \mathrm{C}\right)$. They were fed a commercial pellet diet (type A04 from Panlab, Barcelona, containing $170 \mathrm{~g} \mathrm{~kg}^{-1}$ protein, $587 \mathrm{~g} \mathrm{~kg}^{-1}$ digestible carbohydrates and $30 \mathrm{~g} \mathrm{~kg}^{-1}$ lipids) and tap water $\mathrm{ad}$ libitum.

All rats were implanted with fixed cannulae in the left carotid artery (arterial blood) and the muscular branch of the left femoral vein (Pagès et al. 1993), using polyethylene capillary tubing (Clay-Adams, USA; PE-10; i.d. $0.28 \mathrm{~mm}$; o.d. $0.61 \mathrm{~mm}$ ). Cannulation was performed under ethyl ether anaesthesia. The cannulae were fixed in place with thread knots, filled with heparinized saline and heat-sealed on the free side. They were threaded subcutaneously to exit the rat through its back and kept in place with tape. The cannulae were checked, refilled with heparinized saline and resealed every day for the next 3 days after surgery. The rats resumed their eating patterns (in rhythm and total amount of food ingested) the day after the implantation of cannulae. Surgical stress and anaesthesia were kept to a minimum. All manipulations and treatments inflicted on the rats were carried out in full accordance with the guidelines on care and management of animals established by the European Community.

Cold-exposure was accomplished by moving the rats, inside their cages, to a cold room. The cages were screened against air currents and temperatures were recorded within the cages using thermocouple probes. Temperatures were in the range 3.6-4. ${ }^{\circ} \mathrm{C}$. All cold treatments began at 10:00 h (i.e. $2 \mathrm{~h}$ after the onset of the light period) and were continued for up to $2 \mathrm{~h}$. Under these conditions, the rats were in a postprandial state, since they feed just before the onset of the light period. At 0 , $15,30,60,90$ or $120 \mathrm{~min}$, three series of rats were used for extraction of small blood samples from an artery and a vein: each rat was bled (about $0.1 \mathrm{ml}$ for each vessel) at all the indicated times, yielding about $1 \mathrm{ml}$ in all; i.e. $8 \%$ of its blood. A series of rats was immediately used for the estimation of $\mathrm{pH}$, $P_{\mathrm{O}_{2}}$ and $P_{\mathrm{CO}_{2}}$ using a BMS 3MK2 blood microsystem (Radiometer, Copenhagen, Denmark), calibrated with known standard oxygen and carbon dioxide mixtures. The blood of the second series of animals was used for the measurement of glucose (Trinder, 1969) and lactate (Gutmann and Wahlefeld, 1974) (after perchloric acid deproteinization), total triacylglycerols (Fossati and Prencipe, 1982) and for the estimation of individual amino acids (after trifluoroacetic acid deproteinization) using an Alpha-plus (Pharmacia, Uppsala,
Sweden) amino acid analyzer and a ninhydrin method (Moore and Stein, 1948). The third series of rats was used for the estimation of free fatty acids by means of an enzymatic method using the Nefa C kit (Wako Chemicals GmbH, Neuss, Germany).

A series of rats was sham-cannulated and later used for the estimation of muscle glycogen (Serafini and Alemany, 1987), after being swiftly killed by decapitation. Muscles were frozen in situ with liquid-nitrogen-chilled tongs after the periods of cold-exposure indicated above. Frozen tissue samples were weighed and homogenized in a chloroform:methanol mixture $(3: 1 \mathrm{v} / \mathrm{v})$, in order to extract lipids, and used for the estimation of triacylglycerols (Fossati and Prencipe, 1982). Frozen pieces of muscle from control rats (time 0) and rats exposed to cold for $120 \mathrm{~min}$ were used for the estimation of ATP and creatine phosphate (Heinz and Weisser, 1985), after deproteinization with cold acetone (Soley and Alemany, 1980).

In another series of animals, under ether anaesthesia, one cannula was inserted into the left ventricle via the left carotid artery and another was placed into the left femoral artery. They exited the rat though its back and were filled with heparinized saline. At least $16 \mathrm{~h}$ after surgery, at the same times and after the same periods of cold exposure indicated above, the cannulae were connected to plastic syringes and organ blood flows were measured by means of the injection of $0.100 \mathrm{ml}$ $(50 \mathrm{kBq})$ of ${ }^{46} \mathrm{Sc}$ microspheres (New England Nuclear, mean diameter $15 \mu \mathrm{m}$ ), injected uniformly for $15 \mathrm{~s}$ through the carotid artery cannula. $5 \mathrm{~s}$ before the injection and for the following $60 \mathrm{~s}$, a blood sample was obtained from the femoral artery with a heparinized syringe driven by an infusion pump. This blood sample was weighed and used to give reference blood radioactivity. The rats were then immediately killed and dissected; samples of leg muscle and skin were blotted and weighed, and their radioactivity was determined with a gamma counter. Relative blood flow to each organ was estimated as described previously (Ishishe et al. 1980; Fernández-López et al. 1993), using the formula:

$$
\Phi_{\mathrm{T}}=\left(\Phi_{\mathrm{RB}} \times R_{\mathrm{T}}\right) / R_{\mathrm{RB}},
$$

where $\Phi_{\mathrm{T}}$ is the blood flow to the selected tissue (in $\left.\mathrm{mlmin} \mathrm{mi}^{-1} \mathrm{~g}^{-1}\right), \Phi_{\mathrm{RB}}$ is the reference blood flow sample $\left(\mathrm{ml} \mathrm{min}{ }^{-1}\right), R_{\mathrm{T}}$ is the radioactivity found in the tissue sample (cts $\min ^{-1} \mathrm{~g}^{-1}$ ) and $R_{\mathrm{RB}}$ is the radioactivity of the reference blood sample $\left(\right.$ cts $\left.\min ^{-1}\right)$. Since ${ }^{46} \mathrm{Sc}$ emissions were practically unaffected by the size of the samples used, the data were not corrected for any shielding effect of tissues, and were expressed as cts $\min ^{-1}$ throughout.

Oxygen concentrations were calculated from $P_{\mathrm{O}_{2}}$ (Bork et al. 1975; Boutilier et al. 1977) and the haemoglobin content and dissociation constants of a similar series of rats (Riera et al. 1990). The intracellular and plasma compartments of blood $\mathrm{CO}_{2}$ and bicarbonate were also calculated using standard methods (Severinghaus et al. 1956).

Substrate and gas balances $(B)$ were determined by establishing the differences between the amount of a given 
material $M_{\mathrm{A}}$ carried by the arterial blood reaching the leg and that leaving it, $M_{\mathrm{V}}$ :

$$
B=M_{\mathrm{A}}-M_{\mathrm{V}} .
$$

The values of $M_{\mathrm{A}}$ were derived from the blood flow $\Phi$ and the concentration $m_{\mathrm{A}}$; likewise, $M_{\mathrm{V}}$ was estimated from the same flow $\Phi$ and venous concentrations $m \mathrm{v}$ :

$$
\begin{aligned}
M_{\mathrm{A}} & =\Phi \mathrm{m}_{\mathrm{A}}, \\
M_{\mathrm{V}} & =\Phi m_{\mathrm{V}},
\end{aligned}
$$

then:

$$
B=\Phi\left(m_{\mathrm{A}}-m \mathrm{v}\right) .
$$

Bicarbonate can yield $\mathrm{CO}_{2}$ by consuming $\mathrm{H}^{+}$, so a negative balance of bicarbonate for a given tissue represents the loading of this tissue with an equivalent amount of $\mathrm{H}^{+}$. The small changes in $\mathrm{pH}$ imply tissue neutralization of this load of $\mathrm{H}^{+}$, which means that protons have been used by the mitochondrial oxidative systems to yield water:

$$
\begin{gathered}
\mathrm{HCO}_{3}{ }^{-}+\mathrm{H}^{+} \rightleftharpoons \mathrm{H}_{2} \mathrm{CO}_{3} \rightleftharpoons \mathrm{CO}_{2}+\mathrm{H}_{2} \mathrm{O}, \\
4 \mathrm{H}^{+}+8 \mathrm{e}^{-}+\mathrm{O}_{2} \rightleftharpoons 2 \mathrm{H}_{2} \mathrm{O} .
\end{gathered}
$$

Each mole of oxygen, thus, neutralizes $4 \mathrm{~mol}$ of $\mathrm{H}^{+}$, i.e. $4 \mathrm{~mol}$ of bicarbonate (Casado et al. 1990). Other possible fates for $\mathrm{H}^{+}$include binding to haemoglobin and roles in phosphate and protein buffer equilibria. In most of these other systems, possible drainage of protons occurs at lower concentrations than in the bicarbonate system, however; furthermore, they are directly dependent on $\mathrm{pH}$, a factor that barely changes across the resting muscle of animals subjected to cold exposure. It was assumed that they have less quantitative importance than the direct utilization of $\mathrm{H}^{+}$in the oxidative pathways of the mitochondria. The balances of bicarbonate across the whole hindleg were used to confirm that the amount of oxygen taken up by the tissues was used to maintain the total $\mathrm{H}^{+}$balance (Casado et al. 1990). The hindleg behaved as a net $\mathrm{HCO}_{3}{ }^{-}$ exporter, like the liver (Casado et al. 1990).

The remaining oxygen was assumed to be consumed in the muscle and skin through common oxidative pathways, thus eventually generating heat. A mean value of $6 \mathrm{~mol}$ of ATP produced per mol of $\mathrm{O}_{2}$ consumed was used to express the energy released by the oxidative pathways of the muscle, i.e. its net production of heat. We used the values expressed as $\mu$ mol of ATP to make energy value comparisons between different substrates because it is faster to calculate.

In a similar way, the balances of substrates (glucose, lactate and amino acids) were converted into ATP energy equivalents (only the ATP generated by oxidation), using the more common catabolic pathways described for muscle and the more probable ATP yield found in standard biochemistry texts. We assumed that protein mass was relatively unchanged during this short period, since there is practically no net oxidation of amino acids under these conditions (Adán et al. 1994) compared with oxidation of other substrates. Under shortduration cold exposure, amino acids are used for protein synthesis and pool size variation since the net release of ammonia and glutamine is insignificant (Adán et al. 1994). Thus, we assumed that muscle essentially used glucose and lipid as energy substrates for the whole period studied.

The mean ATP yield from triacylglycerol metabolism was estimated from the mean empirical formulae for fat of this strain of rat (Esteve et al. 1993a), a mean fatty acid chain length and unsaturation level estimated by assuming that each mol of triacylglycerol contained $2.5 \mathrm{~mol}$ of $\mathrm{C} 18: 1$ and $0.5 \mathrm{~mol}$ of C22:2. The free fatty acid energy yield was calculated as one-third of that generated by triacylglycerols, since the glycerol moiety is not used by muscle.

The net oxygen consumption of the tissue (the oxygen balance minus the oxygen used for elimination of excess $\mathrm{H}^{+}$) was used, together with the computed total carbon dioxide released by the tissue (the sum of $\mathrm{CO}_{2}$ and bicarbonate in both main blood pools) to generate the net tissue respiratory quotient, which allowed us to determine the proportion and amount of energy derived from carbohydrate (in the oxidation of glucose, lactate or glycogen, expressed as ATP glucose equivalents) or lipid (oxidation of triacylglycerol, in ATP equivalents). These data, when compared with the actual balances, allowed us to determine whether endogenous substrates had been mobilized or whether their stores had increased.

Statistical comparisons between means were performed using standard analysis of variance (ANOVA) tests, using a significance limit of $P<0.05$.

\section{Results}

Blood flow across the hindleg muscle mass (Fig. 1) increased steadily under cold-exposure for $1 \mathrm{~h}$, followed by a

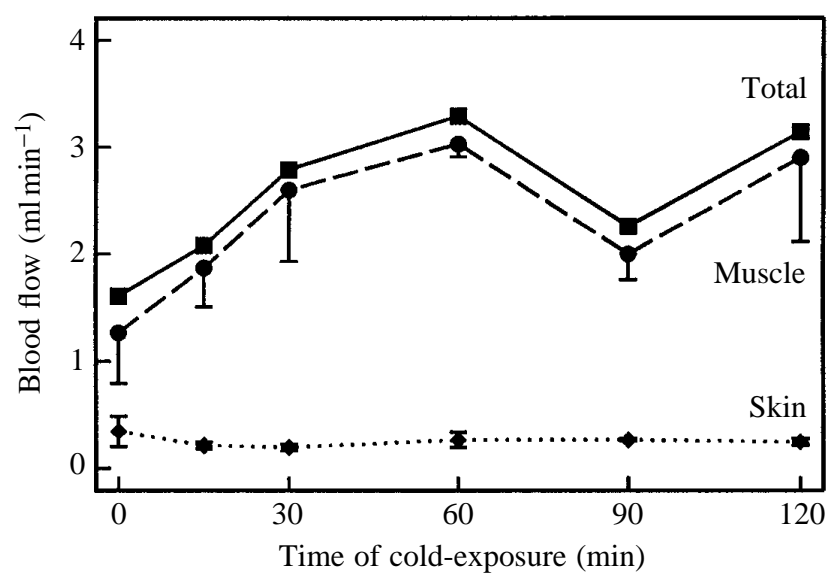

Fig. 1. Blood flow changes in rat hindleg muscle and skin during cold-exposure. The data are means \pm S.E.M. of 4-5 different animals; the total value represents the computed blood flow through hindleg muscle and skin. The mean specific blood flows for muscle were in the range $0.21 \pm 0.08 \mathrm{mlg}^{-1} \mathrm{~min}^{-1}$ at time zero to $0.50 \pm 0.02 \mathrm{ml} \mathrm{g}^{-1} \mathrm{~min}^{-1}$ at $60 \mathrm{~min}$; the mean specific blood flows for skin were in the range $0.13 \pm 0.02 \mathrm{ml} \mathrm{g}^{-1} \mathrm{~min}^{-1}$ at $30 \mathrm{~min}$ to $0.24 \pm 0.07 \mathrm{ml} \mathrm{g}^{-1} \mathrm{~min}^{-1}$ at time zero. There was a statistical change in blood flow to muscle over time (ANOVA, $P<0.05$ ), but not to skin. 


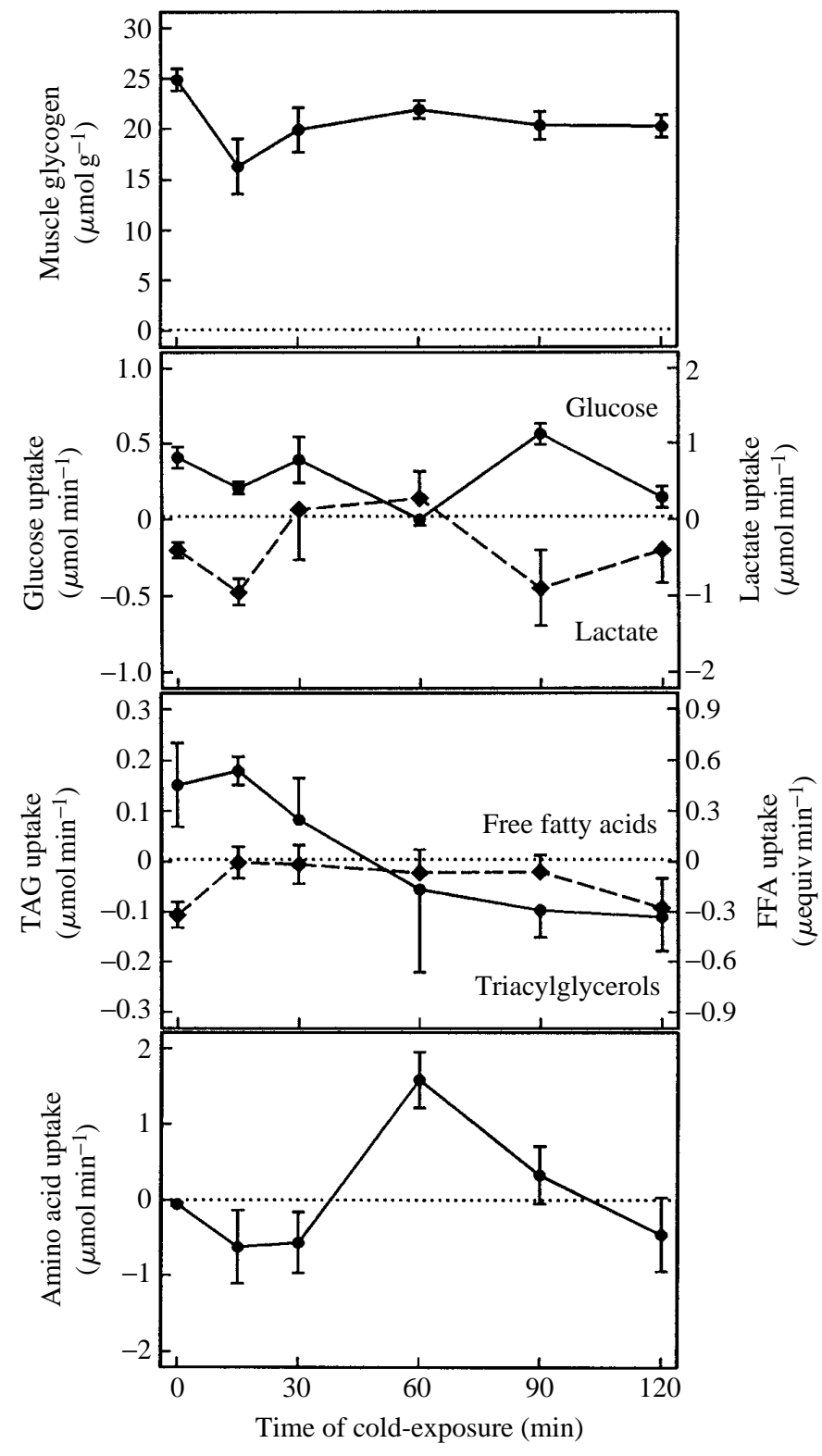

Fig. 2. Glycogen levels and substrate uptake by rat hindleg during cold-exposure. The data are means \pm S.E.M. of 6-7 different animals. Each net uptake (balance) was calculated from the arterio-venous differences in concentration and the mean blood flow for the given time obtained from another set of animals. Positive values represent net uptake by the hindleg, negative values represent net release of substrate. The scales in $\mu$ moles (or $\mu$ equivalents) per minute for triacylglycerols (TAG) and free fatty acids (FFA) are equivalent in terms of ATP generated (i.e. $0.1 \mu \mathrm{mol}$ TAG is equivalent to $0.3 \mu \mathrm{mol}$ FFA). The same can be said for glucose and lactate. There were significant changes in glycogen, triacylglycerol and amino acid uptakes (ANOVA, $P<0.05$ ) over time. There were no significant changes in glucose, lactate or free fatty acid uptakes.

trough at $90 \mathrm{~min}$. Blood flow across the skin changed little. The amount of blood crossing the hindleg muscle of cold-exposed rats was about twice the flow observed at room temperature. The mean mass of hindleg was $16.5 \pm 0.6 \mathrm{~g}$, containing $59.3 \%$ muscle and $20.1 \%$ skin, the rest being essentially bone, claw and sinew.

Fig. 2 shows the balances of glucose, glycogen, lactate, free fatty acids, triacylglycerols and amino acids across the hindleg of rats exposed to $4{ }^{\circ} \mathrm{C}$ for up to $2 \mathrm{~h}$. During the whole period studied, glucose balance was positive, and there were no significant effects of the time of cold-exposure. There was a net lactate production at 0 and $15 \mathrm{~min}$. Lactate efflux increased sharply from 0 to $15 \mathrm{~min}$, decreasing thereafter. Triacylglycerol uptake was practically zero at $60 \mathrm{~min}$, but flow was reversed at 90 and $120 \mathrm{~min}$, since there was now a net fat release by the hindleg.

The net release of free fatty acids from the hindleg was very low during most of the period studied, with values being significantly different from zero (net release) only at time zero. The levels of ATP in muscle did not change between $0 \mathrm{~min}$ $\left(1.73 \pm 0.55 \mu \mathrm{mol} \mathrm{g}^{-1}\right)$ and $120 \mathrm{~min} \quad\left(0.90 \pm 0.23 \mu \mathrm{mol} \mathrm{g}^{-1}\right)$ $(P>0.05)$; nor did those of creatine phosphate change between $0 \mathrm{~min}\left(21.5 \pm 7.5 \mu \mathrm{mol} \mathrm{g}^{-1}\right)$ and $120 \mathrm{~min}\left(10.4 \pm 2.7 \mu \mathrm{mol} \mathrm{g}^{-1}\right)$; the total computed loss of ATP and creatine phosphate of hindleg muscle was approximately $118 \mu \mathrm{mol}$ in $2 \mathrm{~h}$.

Combined amino acid balance at room temperature was almost zero when the whole $120 \mathrm{~min}$ span was considered (mean $61 \mathrm{nmol} \mathrm{min}{ }^{-1}$ ); there was a slight efflux at $15-30 \mathrm{~min}$; however, these values were statistically different from zero only when the combined 15 and 30 min values were considered as a whole, which changed to net uptake at $60 \mathrm{~min}$. The amount of amino acids initially lost was almost equal to that recovered later on.

Table 1 shows the oxygen and carbon dioxide balances of the hindlegs of rats exposed to cold. The changes in arterial or venous $P_{\mathrm{O}_{2}}$ and $\mathrm{P}_{\mathrm{CO}_{2}}$ values with time of cold-exposure were small but significant for $P_{\mathrm{CO}_{2}}$. The variations in $\mathrm{pH}$ were even smaller. The arterio-venous differences in total bicarbonate (intracellular plus plasma) and in total $\mathrm{CO}_{2}$ (free $\mathrm{CO}_{2}$ and bicarbonate in the intracellular and plasma compartments combined) were both small but showed significant increases with cold-exposure; the changes in the net contribution of the hindleg to total $\mathrm{CO}_{2}$ balance were not significant, despite showing a tendency to rise shortly after the beginning of coldexposure and to decrease later. Arterial and venous blood oxygen concentrations were not significantly affected by coldexposure, but the proportion of oxygen carried in the blood that was taken up and used by the leg tended to increase with the cold. The corresponding $\mathrm{CO}_{2}$ and oxygen balances, however, changed markedly with cold-exposure, as the net production of $\mathrm{CO}_{2}$ increased and the consumption of $\mathrm{O}_{2}$ tended to increase. Since the balance of bicarbonate also increased, the portion of oxygen needed to equilibrate the balance of bicarbonate $\left(\mathrm{H}^{+}\right)$ was, on average (despite wide individual variations), doubled with cold-exposure. The corrected mean respiratory quotient (total $\mathrm{CO}_{2}$ /oxygen consumed minus that used for elimination of bicarbonate-derived protons) increased with cold-exposure to a peak at $15 \mathrm{~min}$, decreasing thereafter to a steady figure close to 0.7 .

The energy equivalence of the balances shown in Fig. 2 and 
Hindleg energy balance during cold-exposure 1247

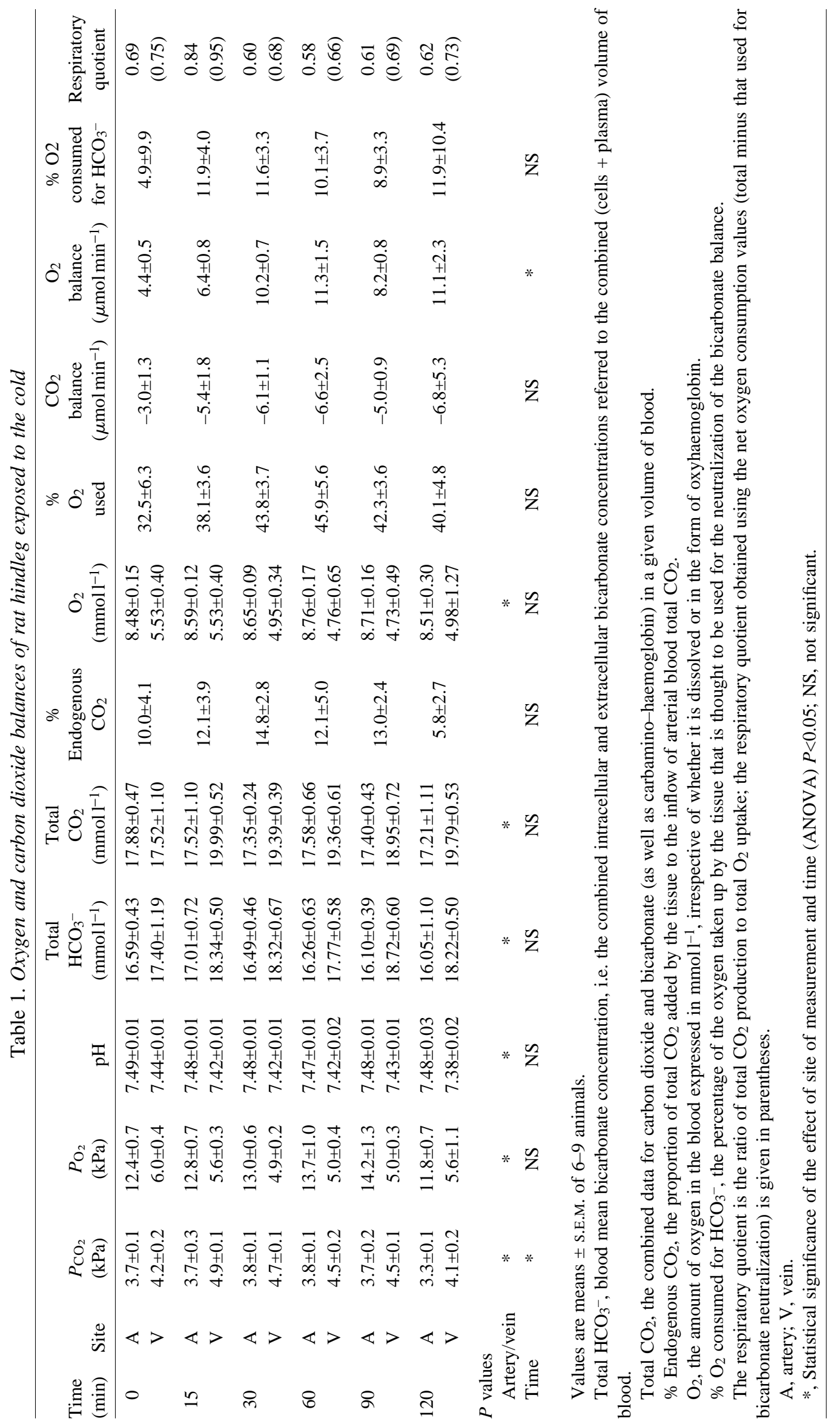


Table 2. Energy equivalence of net balances of substrates in the hindleg of the rat during exposure to the cold

\begin{tabular}{|c|c|c|c|c|c|c|}
\hline \multirow[b]{2}{*}{ Substrate } & \multicolumn{6}{|c|}{ Duration of cold-exposure ( $\mathrm{min}$ ) } \\
\hline & 0 & 15 & 30 & 60 & 90 & 120 \\
\hline Glucose & 12.2 & 6.2 & 11.7 & 0.0 & 16.8 & 4.4 \\
\hline Lactate & -6.4 & -16.0 & 1.6 & 4.8 & -14.4 & -6.4 \\
\hline Triacylglycerols & 63 & 75 & 34 & -23 & -41 & -45 \\
\hline Free fatty acids & -42.0 & -0.8 & -2.3 & -9.1 & -8.3 & -38.0 \\
\hline Alanine & -1.8 & -4.8 & 0.0 & 2.8 & 1.6 & -2.7 \\
\hline Glutamate & 5.6 & 1.1 & -0.3 & 4.5 & 2.3 & 2.1 \\
\hline Glutamine & 5.6 & -3.6 & -7.2 & 11.5 & -0.8 & -1.0 \\
\hline Aspartate & -0.7 & -2.2 & -4.9 & 0.5 & -1.9 & -3.1 \\
\hline Leucine & -0.1 & -0.6 & -7.7 & 5.3 & 1.4 & 1.6 \\
\hline Isoleucine & -0.9 & 0.6 & 1.5 & 4.1 & -1.3 & 1.2 \\
\hline Valine & -1.7 & -0.3 & 0.9 & 1.9 & 1.0 & 3.4 \\
\hline$\Sigma$ Amino acids & 1.6 & -9.8 & -17.7 & 30.6 & 2.3 & 1.5 \\
\hline $\begin{array}{l}\Sigma \text { Total (minus } \\
\text { amino acids) }\end{array}$ & 26.8 & 64.4 & 45.0 & -27.3 & -46.9 & -85.0 \\
\hline$\Sigma$ Total & 34.4 & 54.6 & 27.3 & 3.3 & -44.6 & -83.5 \\
\hline Oxygen (total) & 26.3 & 38.4 & 61.4 & 67.5 & 49.1 & 66.6 \\
\hline Oxygen (net) & 25.0 & 33.8 & 54.3 & 60.7 & 44.7 & 58.7 \\
\hline
\end{tabular}

Energy equivalents are expressed in $\mu \mathrm{mol}$ ATP min ${ }^{-1}$.

The data are the calculated means for each material from the net balances at each exposure time.

The equivalence in ATP generated through the oxidative energy pathway (in $\mu \mathrm{mol}$ ATP $\mu \mathrm{mol}^{-1}$; i.e. the ATP obtained through direct substrate phosphorylation was not taken into account) of the substrates used for calculations was: glucose, 30; lactate, 16; triacylglycerols, 420 (mean fatty acid composition: $2.5 \mathrm{C} 18: 1,0.5$ C22:2); free fatty acids, 140; alanine, 14; glutamate or glutamine, 23; aspartate, 17; leucine or isoleucine, 38; valine, 24.

Positive values represent net substrate uptake by the hindleg and negative values represent net substrate release from internal stores (endogenous energy).

Total oxygen-derivable energy represents the crude conversion of the oxygen balance to ATP energy (6 mol ATP per mol $\left.\mathrm{O}_{2}\right)$.

Net oxygen-derivable energy is this value after the oxygen needed for neutralizing the bicarbonate $/ \mathrm{H}^{+}$balance has been discounted.

Table 1 are presented in Table 2, which shows the energy flow equivalences (in $\mu \mathrm{mol} \mathrm{ATP} \mathrm{min}^{-1}$ ) of the balances for glucose, lactate, triacylglycerols, free fatty acids, amino acids and oxygen. Only the amino acids known to be oxidized (branched chain: leucine, isoleucine and valine), actively synthesized or used (alanine, glutamine, glutamate and aspartate) were included in this study, since all other changes must reflect changes in pool size or protein mass. Total substrate uptake essentially followed the pattern for triacylglycerol, whose contribution to hindleg energy balance was maximal at room temperature and shortly after the start of cold-exposure, reverting to a severe drainage of energy from 60 min onwards. Despite this reversal of substrate uptake from the blood, oxygen consumption first increased and was later maintained at higher levels during cold-exposure.
Table 3. Energy equivalence of net balances of carbohydrate and lipid in the hindleg of the rat during exposure to the cold compared with the calculated consumption derived from oxygen consumption and respiratory quotient

\begin{tabular}{lcccccr}
\hline & \multicolumn{7}{c}{ Duration of cold-exposure (min) } \\
\cline { 2 - 7 } Variables & 0 & 15 & 30 & 60 & 90 & 120 \\
\hline Percentage of substrate oxidized & & & & & \\
$\quad$ Carbohydrate & 17 & 83 & 0 & 0 & 0 & 10 \\
$\quad$ Lipid & 83 & 17 & 100 & 100 & 100 & 90 \\
Lipid consumption & & & & & & \\
$\quad$ Oxidized & 20.8 & 5.7 & 45.3 & 60.7 & 44.7 & 52.8 \\
$\quad$ Balance & 21.0 & 74.2 & 31.7 & -32.1 & -32.7 & -83.0 \\
$\quad$ Net endogenous & -0.2 & -68.5 & 22.6 & 92.8 & 77.4 & 136.0 \\
Carbohydrate consumption & & & & & \\
$\quad$ Oxidized & 4.2 & 28.1 & 0 & 0 & 0 & 5.9 \\
$\quad$ Balance & 5.8 & -9.8 & 13.3 & 4.8 & 2.4 & -2.0 \\
$\quad$ Net endogenous & -1.6 & 37.9 & -13.3 & -4.8 & -2.4 & 7.9 \\
$\quad$ Muscle glycogen & 0.0 & 166 & -68.6 & -9.8 & 10.0 & -0.4 \\
& & & & & &
\end{tabular}

Energy equivalents are expressed in $\mu \mathrm{mol} \mathrm{ATP} \mathrm{min}^{-1}$.

All values have been calculated from the data shown in Tables 1 and 2 and Figs 1 and 2. The percentage of substrate oxidized has been derived from the respiratory quotient presented in Table 1, assuming an almost insignificant protein oxidation in muscle for the whole period studied.

All consumption values are expressed as aerobic ATP equivalents

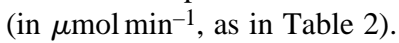

Oxidized lipid and carbohydrate values were obtained from the net oxygen balance (expressed in oxidative ATP equivalents) and the percentage of each substrate oxidized derived from the respiratory quotient.

The lipid balance is the sum of the balances of triacylglycerol and free fatty acid balances, and that of carbohydrate is the sum of the balances of glucose and lactate. The amount supplied from endogenous sources is the difference between the calculated amount of substrate oxidized and the net substrate balances. The glycogen levels presented correspond only to those in muscle (Fig. 2).

Table 3 elaborates on the data in the previous figures and tables, illustrating the proportion of oxygen energy equivalents derived from lipid or carbohydrate, calculated from the standard respiratory quotients of 1.0 for carbohydrate and 0.7 for lipid, assuming a negligible oxidation of amino acids.

Lipid (triacylglycerol plus free fatty acid) consumption was minimal at $15 \mathrm{~min}$ of cold-exposure, falling below the already low rate of consumption at room temperature. It increased considerably from 30 min onwards to sustain practically all the energy needs of the whole hindleg. The balance of triacylglycerols carried by the blood changed sign between 30 and $60 \mathrm{~min}$ of cold-exposure, so the result is a marked alteration of internal fat pool management after cold-exposure: net uptake of triacylglycerols (and consequent build-up of fat reserves) at room temperature and shortly after cold-exposure changes to a significant mobilization of fat reserves, accounting not only for the whole net oxidative energy 
produced but also the release of triacylglycerols to the bloodstream for use elsewhere.

No significant changes were observed in triacylglycerol mass in muscle (mean 17.2 $\pm 2.1 \mu \mathrm{mol} \mathrm{g}^{-1}$ ) and skin (mean $130 \pm 7 \mu \mathrm{mol} \mathrm{g}^{-1}$ ) during the period studied (ANOVA). The triacylglycerol energy stored in the hindleg muscle and skin tissue amounted to a mean of $603 \mu \mathrm{mol}$ (i.e. $494 \mathrm{mg}$ ), which would represent about $249 \mathrm{mmol}$ of ATP if it were oxidized under standard conditions. The computed loss of triacylglycerol (oxidized or carried away with the blood) by leg tissues during the $120 \mathrm{~min}$ of cold-exposure was equivalent to $6.7 \mathrm{mmol}$ of ATP. The loss during the second hour of coldexposure was equivalent to $6.1 \mathrm{mmol}$ of ATP. This result indicates that, in all, the leg lost about $2.7 \%$ of its lipid energy in $2 \mathrm{~h}$; in addition, it suggests that all hindleg lipid could be consumed in about $41 \mathrm{~h}$ if the oxidative and efflux rates were maintained.

Carbohydrate consumption was low at room temperature, but increased sharply shortly after exposure to $4{ }^{\circ} \mathrm{C}$, decreasing to practically zero from 30 min of exposure onwards. When the data on glucose plus lactate balances are combined with the carbohydrate oxidation energy derived from net oxygen uptake and the respiratory quotient, the results indicate a marked draining of glycogen in the whole hindleg, which coincides with the observed decrease in muscle glycogen content. Immediately after this period, there is a slow recovery of the internal carbohydrate pools, at the expense of glucose and lactate balance, which again coincides with a recovery of muscle glycogen levels.

Each hindleg mass represents about $6.6 \%$ of the rat mass, containing about $9.1 \%$ of the muscle mass of the rat, a mean $43 \%$ of body mass (Arola et al. 1979). The hindleg consumes only $1.8 \%$ of the rat's oxygen supply (Esteve et al. 1993b) under standard conditions (time zero) and $1.9 \%$ during coldexposure (120 min).

\section{Discussion}

The interpretation, in terms of energy, of oxygen arteriovenous balances in many tissues has often been used as a means of establishing the energy consumption of a given organ or part of live animals (Barbee et al. 1983). Despite their considerable interest, however, organ respiratory quotients have seldom been used (Ahlborg et al. 1974), partly because of the uncertainties posed by the measurement of exact levels of carbon dioxide in its different forms (bicarbonate, carbamino-haemoglobin, free $\mathrm{CO}_{2}$ ) in the main blood compartments. This problem has largely been solved, thanks to precise measurements of haemoglobin dissociation constants and the Bohr effect (Bork et al. 1975; Boutilier et al. 1977; Riera et al. 1990), as well as by straightforward calculation of relationships between $\mathrm{P}_{\mathrm{CO}_{2}}, \mathrm{pH}$ and the actual concentrations of these 'total $\mathrm{CO}_{2}$ ' components (Severinghaus et al. 1956). The measurement of balances of oxygen and carbon dioxide across a given tissue, however, often results in relatively low values for total $\mathrm{CO}_{2}$ compared with oxygen consumption (Casado et al. 1990). The inter-organ transfer of 'oxygen debt' in the form of bicarbonate-linked protons (Casado et al. 1990) permitted the correction of these data to give lower oxygen consumption figures that were directly related to the metabolic processes of substrate oxidation. We have thus been able to obtain a corrected respiratory quotient and to use it to establish the possible use of tissue carbohydrate or lipid stores.

Mammalian muscle maintains an active amino acid metabolism in the postprandial state, providing considerable amounts of alanine, glutamine and other amino acids (Ruderman, 1975) for splanchnic energy and glyconeogenesis (Aikawa et al. 1973). The overall flow of amino nitrogen from the peripheral (mainly muscle and adipose tissue) organs to the splanchnic bed is changed after eating, when these organs take up most of the substrates released by the intestine (FernándezLópez et al. 1993). Our experiment was scheduled to begin $2 \mathrm{~h}$ after the last bout of feeding, which occurs shortly before the onset of the light period (Calhoun, 1963), but not so long after feeding for the rat to be in a postprandial state. The idea was to limit the influence of amino acid interchange and thus to minimize its effect on the respiratory quotient. The relatively small alanine and glutamine effluxes were in agreement with this interpretation, since alanine and glutamine are the main nitrogen-bearing compounds released by muscle under conditions of limited proteolysis (Aikawa et al. 1973). Evidently some proteolysis and, later on, net protein synthesis occurred in the cold-exposed hindleg, but its effect as an energy-supplying substrate is very small (Adán et al. 1994) compared with those of carbohydrate and lipid (Table 2). In fact, the changes observed in amino acid uptake correspond essentially to variations in pool size and protein turnover, not to actual amino acid oxidation for energy purposes (Adán et al. 1994).

The noteworthy constancy of arterial oxygen concentration, as well as the scarcely changing $\mathrm{pH}$ and $\mathrm{P}_{\mathrm{CO}_{2}}$, indicate that the main element of change was the alteration of blood flow induced by cold-exposure. In cold-acclimated rats, blood flow across brown adipose tissue masses increases dramatically (López-Soriano et al. 1988), with a relative skin vasoconstriction (Foster and Frydman, 1978) such as that observed here. Skeletal muscle blood flow increases with coldexposure and the onset of shivering. Hindleg muscle temperature decreases more than that of the core blood under cold-exposure, however (Closa et al. 1992), apparently because heat losses through conduction to the skin and the environment tend to equilibrate blood-borne heat and the heat produced by the leg, which consists mainly of muscle tissue. It is improbable that muscle heat production would contribute significantly to the maintenance of core temperature (Closa et al. 1992), so the role of shivering would be more related to maintaining of muscle temperature itself than to making a substantial contribution to overall thermoregulation. In the rat, muscle temperature decreases only a couple of degrees under cold exposure when compared with aortic temperature (Closa et al. 1992), the temperature of muscle being maintained only 
partly by muscle metabolism and mainly through heat transfer from the blood (Adán et al. 1995).

The muscle used less energy before exposure to cold than afterwards; most of the energy then used was of lipid origin. Combined amino acid uptake was almost zero, and the proportion of glucose used was relatively small, with a high proportion of it being returned to the bloodstream in the form of lactate. There was probably not a significant rise in tissue lactate levels, since lactate exchange with the bloodstream was low: a balance of practically zero and low circulating levels. The basal conditions used in this experiment suggested a significant accumulation of lipid energy and a reduced use of glucose. Shortly after the ambient temperature was reduced to $4{ }^{\circ} \mathrm{C}$, the energy production (oxygen consumption) of the muscle increased (Poole et al. 1992), following a pattern similar to that of light exercise, with a significant use of the glycolytic pathway and increased lactate efflux (Ahlborg et al. 1974; Barbee et al. 1983), essentially at the expense of muscle glycogen (Price et al. 1991), levels of which decreased by $35 \%$. This transient period could be related to the onset of shivering (Gautier et al. 1991). Shortly thereafter, however, the muscle forfeited its active glycolytic conversion of glucose to lactate (lactate production dropped to zero, as did glucose net uptake) and fats became almost the sole source of energy.

The period studied shows three well-defined phases of substrate handling by cold-exposed hindleg. (1) The onset of shivering, with the use of glucose/glycogen through the glycolytic pathway and an increase in lactate efflux. Most of the energy comes from increased substrate oxidation. There is practically no lipid oxidation, and the uptake of triacylglycerols from the blood remains unchanged. (2) A substrate-energy shift, with a marked decrease in the use of glucose/glycogen and diminished lactate efflux. Triacylglycerol is almost the sole source of energy. There is a decreased uptake of triacylglycerol and increased tissue lipid mobilization. (3) A new heat-homeostasis setting for prolonged cold-exposure, with the maintenance of muscle energy and heat production being based on fat utilization, and triacylglycerol efflux from the hindleg (muscle plus skin and subcutaneous adipose masses) contributing energy to help sustain heat production by the core organs and surrounding brown adipose tissue masses. Phase 3 is like the peripheral tissue lipid mobilization that occurs during cold-adaptation (or prolonged cold-exposure) in the rat (Vallerand and Jacobs, 1989). After $120 \mathrm{~min}$ of cold-exposure, the rat energy budget and distribution have changed sharply and the mechanisms of long-term adaptation to the cold begin to take hold, resulting in full cold-acclimation after a longer and sustained period of cold-exposure.

The most striking effect observed is the dramatic decrease of glucose utilization (phase 2) occurring shortly after the bout of glycolysis that characterized the onset of shivering (phase 1). The lower respiratory quotient marks a shift in the uptake/release of fats from/to the blood and supports this interpretation; this active fat mobilization may be related to the need to maintain muscle glycogen levels as a fuel for occasional muscle work, muscle thermogenesis being fuelled from widely available fat stores.

This work was supported by a grant from the Plan Nacional de Investigación Científica y Desarrollo Tecnológico de la Comisión Interministerial de Ciencia y Tecnología (DEP910736) from the Government of Spain. A.A. is the recipient of a predoctoral fellowship of the Government of Catalonia. Thanks are given to Robin Rycroft for the literary correction of the manuscript.

\section{References}

AdÁn, C., Ardévol, A., Closa, D., Remesar, X., Alemany, M. And FERNÁNDEZ-LóPEZ, J. A. (1995). Hind leg heat losses of coldadapted rats. J. therm. Biol. (in press).

Adán, C., Ardévol, A., Remesar, X., Alemany, M. And FERNÁNDEZ-LóPEZ, J. A. (1994). Hind leg muscle amino acid balances in cold-exposed rats. Molec. cell. Biochem. 130, 149-157.

Ahlborg, G., Felig, P., Hagenfeldt, L., Hendler, R. And Wahren, J. (1974). Substrate turnover during prolonged exercise in man. $J$. clin. Invest. 53, 1080-1090.

Aikawa, T., Matsutaka, H., Yamamoto, H., OKUda, T., IshiKawa, E., Kawano, T. and Matsumura, E. (1973). Glyconeogenesis and amino acid metabolism. II. Inter-organal relation and roles of glutamine and alanine in the amino acid metabolism of fasted rats. J. Biochem., Tokyo 74, 1003-1017.

Arola, L., Herrera, E. And Alemany, M. (1979). A method for the estimation of striated muscle mass in small laboratory animals. Rev. esp. Fisiol. 35, 215-218.

Barbee, R. W., Stainsby, W. N. And Chirtel, S. J. (1983). Dynamics of $\mathrm{O}_{2}, \mathrm{CO}_{2}$, lactate and acid exchange during contractions and recovery. J. appl. Physiol. 54, 1687-1692.

Bork, R., Vaupel, P. And Thews, G. (1975). Atemgas-pHnormogramme für das Rattenblut bei $37^{\circ} \mathrm{C}$. Anaesthetist 24, 84-90.

Boutilier, R. G., Gibson, M. A., Toews, D. P. And Anderson, N. (1977). Gas exchange and acid-base regulation in the blood and extraembryonic fluids of the developing chick embryo. Respir. Physiol. 31, 81-89.

BRÜCK, K. AND ZEISBERgER, K. (1987). Adaptive changes in thermoregulation and their neuropharmacological basis. Pharmac. Therap. 35, 163-215.

Bukowiecki, L., Folleá, N., Vallières, J. And Leblanc, J. (1978) $\beta$-Adrenergic receptors in brown-adipose tissue. Characterization and alterations during acclimation of rats to cold. Eur. J. Biochem. 92, 189-196.

Calhoun, J. B. (1963). The Ecology and Sociology of the Norway Rat. Bethesda, MD: US Department of Health, Education and Welfare.

Casado, J., Fernández-López, J. A., Esteve, M., Rafecas, I., Argilés, J. M. AND Alemany, M. (1990). Rat splanchnic net oxygen consumption, energy implications. J. Physiol., Lond. 431, 557-569.

Closa, D., Alemany, M. and Remesar, X. (1992). Effect of cold exposure on organ temperatures in Wistar and Zucker fa/fa rat. $J$. therm. Biol. 17, 83-88.

Davis, T. R. A., Johnston, D. R., Bell, F. C. And Cremer, H. J. (1960). Regulation of shivering and nonshivering heat production during acclimation of rats. Am. J. Physiol. 198, 471-475.

Esteve, M., Rafecas, I., Fernández-LóPez, J. A., Remesar, X. And 


\section{Hindleg energy balance during cold-exposure 1251}

Alemany, M. (1993a). Dietary fatty acid utilization by young Wistar rats fed a cafeteria diet. Molec. cell. Biochem. 118, 67-74.

Esteve, M., Rafecas, I., Fernández-LóPez, J. A., Remesar, X. AND Alemany, M. (1993b). Lipid synthesis: a thermogenic mechanism in cold-exposed Zucker fa/fa rats. Comp. Biochem. Physiol. A 105, 369-376.

Fernández-López, J. A, Casado, J., Esteve, M., Rafecas, I., Argilés, J. M., Remesar, X. AND Alemany, M. (1993). Intestinal and hepatic nitrogen balance in the rat after the administration of an oral protein load. Brit. J. Nutr. 69, 733-742.

Fossati, P. AND PRencipe, L. (1982). Serum triglycerides determined colorimetrically with an enzyme that produces hydrogen peroxide. Clin. Chem. 28, 2077-2080.

Foster, D. O. AND Frydman, M. L. (1978). Tissue distribution of cold-induced thermogenesis in conscious warm- or cold-acclimated rats reevaluated from changes in tissue blood flow: the dominant role of brown adipose tissue in the replacement of shivering by nonshivering thermogenesis. Can. J. Physiol. Pharmac. 57, 257-270.

Fregly, M. J., Kikta, D. C., Threatte, R. M., Torres, J. L. AND BARNEY, C. C. (1989). Development of hypertension in rats during chronic exposure to cold. J. appl. Physiol. 66, 741-749.

Gautier, H., Bonora, M., M'barek, S. B. and Sinclair, J. D. (1991). Effects of hypoxia and cold acclimation on thermoregulation in the rat. J. appl. Physiol. 71, 1355-1363.

Gordon, C. J. (1990). Thermal biology of the laboratory rat. Physiol. Behav. 47, 963-991.

Gutmann, I. AND Wahlefeld, A. W. (1974). L-(+)-lactate. In Methods of Enzymatic Analysis, vol. 4 (ed. H. U. Bergmeyer.), pp. 1464-1468. New York: Academic Press.

Heinz, F. And Weisser, H. (1985). Creatine phosphate. In Methods of Enzymatic Analysis, vol. 8 (ed. H. U. Bergmeyer, J. Bergmeyer and M. Grassl), pp. 507-514. Weinheim: VCH Verlagsgesselschaft.

Iossa, S., BarlettA, A. AND Liverini, G. (1991). Hepatic selective adjustments in short-term cold exposed rats. Cell. Biochem. Funct. 9, 275-280.

Ishishe, S., Pegram, B. L., Yamamoto, J., Kitamura, Y. And FroHLich, E. D. (1980). Reference sample microsphere method: cardiac output and blood flows in conscious rats. Am. J. Physiol. 239, H433-H449.

KLEIBER, M. (1972). Body size, conductance for animal heat flow and Newton's law of cooling. J. theor. Biol. 37, 139-150.
López-Soriano, F. J., Fernández-López, J. A., Mampel, T., Villarroya, F., Iglesias, R. and Alemany, M. (1988). Amino acid and glucose uptake by rat brown adipose tissue. Effect of coldexposure and acclimation. Biochem. J. 252, 843-849.

Moore, S. And Stein, W. H. (1948). Photometric ninhydrin method for use in the chromatography of amino acids. J. biol. Chem. 176, 367-388.

Pagès, T., Fernández-López, J. A., Adán, C., Gámez, A., Viscor, G. AND PALACIOS, L. (1993). A method for sampling representative muscular venous blood during exercise in rats. Lab. Animals 27, 171-175.

Poole, D. C., Gaesser, G. A., Hogan, M. C., Knight, D. R. And WAGNER, P. D. (1992). Pulmonary and leg $V_{\mathrm{O}_{2}}$ during submaximal exercise: implications for muscular efficiency. J. appl. Physiol. 72, 805-810.

Price, T. B., Rothman, D. L., Avison, M. J., Buonamico, P. And Shulman, R. G. (1991). ${ }^{13}$ C-NMR measurements of muscle glycogen during low-intensity exercise. J. appl. Physiol. 70, 1836-1844.

Riera, M., SÁnchez, J., RAMA, R. AND Palacios, L. (1990). Changes in haemoglobin oxygen affinity in ethanol-treated rats. Influence of intraerythrocytic phosphates. Gen. Pharmac. 21, 290-293.

Ruderman, N. B. (1975). Muscle amino acid metabolism and glyconeogenesis. A. Rev. Med. 26, 245-248.

Serafini, M. T. And Alemany, M. (1987). A micromethod for the enzymatic estimation of the degree of ramification of glycogen. $J$. biochem. biophys. Meth. 15, 33-39.

Severinghaus, J. W., Stupfel, M. and Bradley, A. F. (1956). Accuracy of blood $\mathrm{pH}$ and $\mathrm{P}_{\mathrm{CO}_{2}}$ determinations. J. appl. Physiol. 9, 189-196.

Soley, M. And Alemany, M. (1980). A rapid method for the estimation of amino acid concentration in liver tissue. J. biochem. biophys. Meth. 2, 207-211.

TRINDER, P. (1969). Determination of glucose in blood using glucose oxidase with an alternative oxygen acceptor. Annls clin. Biochem. 6, 24-27.

VALleRAND, A. L. AND JACOBS, I. (1989). Rates of energy substrates utilization during human cold exposure. Eur. J. appl. Physiol. 58, 873-878.

YahatA, T. AND KuROShima, A. (1988). Metabolic cold acclimation after repetitive intermittent cold exposure in rat. Jap. J. Physiol. 39, 215-228. 